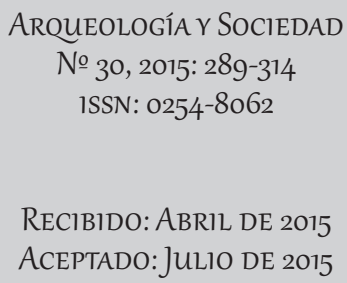

RECIBIDO: ABRIL DE 2015

ACEPTADO:JUL1O DE 2015

\title{
MAMA SIMONA: MEMORIA ANCESTRAL Y CONTEMPORÁNEA
}

\author{
WiLBER Bolívar YAPURA \\ UNIVERSIDAD NACIONAL SAN ANTONIO DE ABAD \\ wilberbolivar@gmail.com
}

\section{RESUMEN}

El presente trabajo se centra en comprender a una de las montañas más importantes que rodean al valle del Cusco, que en épocas prehispánicas fue un Apu tutelar muy importante, y que su denominacion fue cambiando de acuerdo a las coyunturas de los actores sociales de esos tiempos, cuya vigencia se mantiene aún. Esta recibió diferentes nombres como Apian, Aspiran y Yauira, de nuevo Aspiran, otra vez Apian y Yauirac desde 1571 hasta 1653 anotado por los cronistas de esas épocas. Luego con la extirpación de idolatras se le asigna el nombre de Simón que fue quechuizado a Quimon y finalmente el de Mama Simona ya convertida en una montaña con espíritu femenino. Cuya importancia es explicada por el rol que desempeña en la memoria ancestral y su reivindicación como tal en nuestros tiempos.

Palabras Clave: Montaña, Mama Simona, Apu, Deidad, Espíritu Femenino, Simón, Quimon.

\section{Abstract}

This work focuses on understanding one of the most important mountains surrounding the valley of Cusco, in pre-Hispanic times it was a tutelary Apu very important, and that its name was changed according to the situations of social actors of those times, whose validity still remains . It is given different names like Apian, aspire and Yauira, again aspire, again Apian and Yauirac from 1571-1653 recorded by chroniclers of those times. Then with the removal of idolaters is assigned the name of Simon who was quechuizado to Quimon and finally the Mama Simona and converted into a female mountain spirit. Whose importance is explained by the role it plays in the ancestral memory and its claim as such in our times.

KEYWoRDS: Mountain, Mama Simona, Apu, Deity, Female spirit, Simón, Qzuimon. 


\section{INTRODUCCIÓN}

Nuestro propósito al iniciar este trabajo fue el de indagar su importancia y vigencia además del porqué esta montaña estaba pasando a segundo nivel y olvidándose en la memoria colectiva de los residentes de los distritos Ccorqa, Poroy incluido el valle del Cusco, que es el área inmediata de influencia a pesar que destaca en el paisaje sagrado circunscripto al valle del Cusco. En los trabajos de investigación referidos a las montañas o Apus Tutelares del Cusco no se la inscribe como tal ni tampoco se la correlaciona con los Seques y Wakas, a pesar de estar dentro de la clasificación jerárquica socio política con el término de Payan (segundo). Por otro lado este Apu, está ubicado en la línea de frontera o división de dos suyos el de Contisuyo (Ccorqa) y Chinchaysuyo (Poroy) cuyas denominaciones correspondieron a Upuyauira y Apian.

Para contextualizarnos en su territorio de influencia nos introducimos en reconocer su ubicación y colindancias, para luego hacer una descripción del Apu Mama Simona, con sus dos sectores Cima y Estructuras, sin dejar de lado su geomorfología. Revisamos los antecedentes etnohistóricos y las investigaciones relacionadas con nuestro tema de estudio correlacionando los Apus en el sistema de Wak'as, que son fuentes de vida e inducen la reproducción así como de ser protectores y sanadores que a su vez otorgan y distribuyen el agua. De igual modo, percibir a Mama Simona en nuestros días y de cómo los actores sociales participan reconociéndola como tal, ofreciéndole ofrendas antes y en actualidad.

También nos introducimos en reconocer su parentela sagrada, las denominaciones que recibe, a las montañas como objetos de culto en su espacio con poder en un paisaje sagrado, con caminos especiales orientados hacia los adoratorios de altura, para finalmente reflexionar a través de una aproximación final.

Ubicación: Mama Simona, se ubica en la comunidad campesina de Quishuarcancha, distrito de Ccorca, provincia y departamento del Cusco, exactamente hacia el noroeste de Ccorca, sobre un cerro denominado con el mismo nombre, en la zona UTM 18, cuadricula 18-L y Carta Nacional 28 R (Tambobamba), la coordenada de referencia es 0819249.9460 Este y 8500204.8610 Norte (sistema WGS84), con una altitud de 4136.439 m.s.n.m. Según la propuesta de delimitación cuenta con un área de $423022.5833 \mathrm{~m}^{2}(42.3022 \mathrm{Ha})$ y un perímetro de 2961.165 metros lineales. Para llegar al mencionado sitio arqueológico se toma la trocha carrozable que se desplaza de Cusco hacia Ccorca, en el trayecto al pie de carretera se encuentra la comunidad campesina de Quishuarcancha, lugar desde el cual se emprende una caminata de leve ascenso por un camino ceremonial hacia el Apu Mama Simona, en aproximadamente 1 hora y 30 minutos.

Colindancias: Por el Norte con la ladera del Apu Mama Simona, por el Este con área de pastizales y terrenos de cultivo temporal, por el Sur con la ladera del Apu Mama Simona y por el Oeste con el camino peatonal hacia la quebrada de Mutuycancha.

Descripción del Apu Mama Simona: El cerro con delicadas formas faciales femeninas; se encuentra ubicado a medio camino del distrito de Ccorca, a $3 \mathrm{~km}$ de la comunidad de Quishuarcancha, desde este punto se desprende un camino ceremonial prehispánico que va en dirección al Apu (Apian, Aspira, Yauira y hoy denominada como Mama Simona), esta tiene una altura de 4,136.439 msnm. Se alza a la cabecera del valle, como quien intenta alcanzar con la vista a los Apus Awsangati y Salkantay. Está dividida en dos sectores.

Sector Cima: Es la parte más alta desde donde se tiene una visualización de $360^{\circ}$, con esta panorámica iniciando en el lado oeste se puede divisar el valle de Anta (Xaquihauana) y al fondo al poderoso 


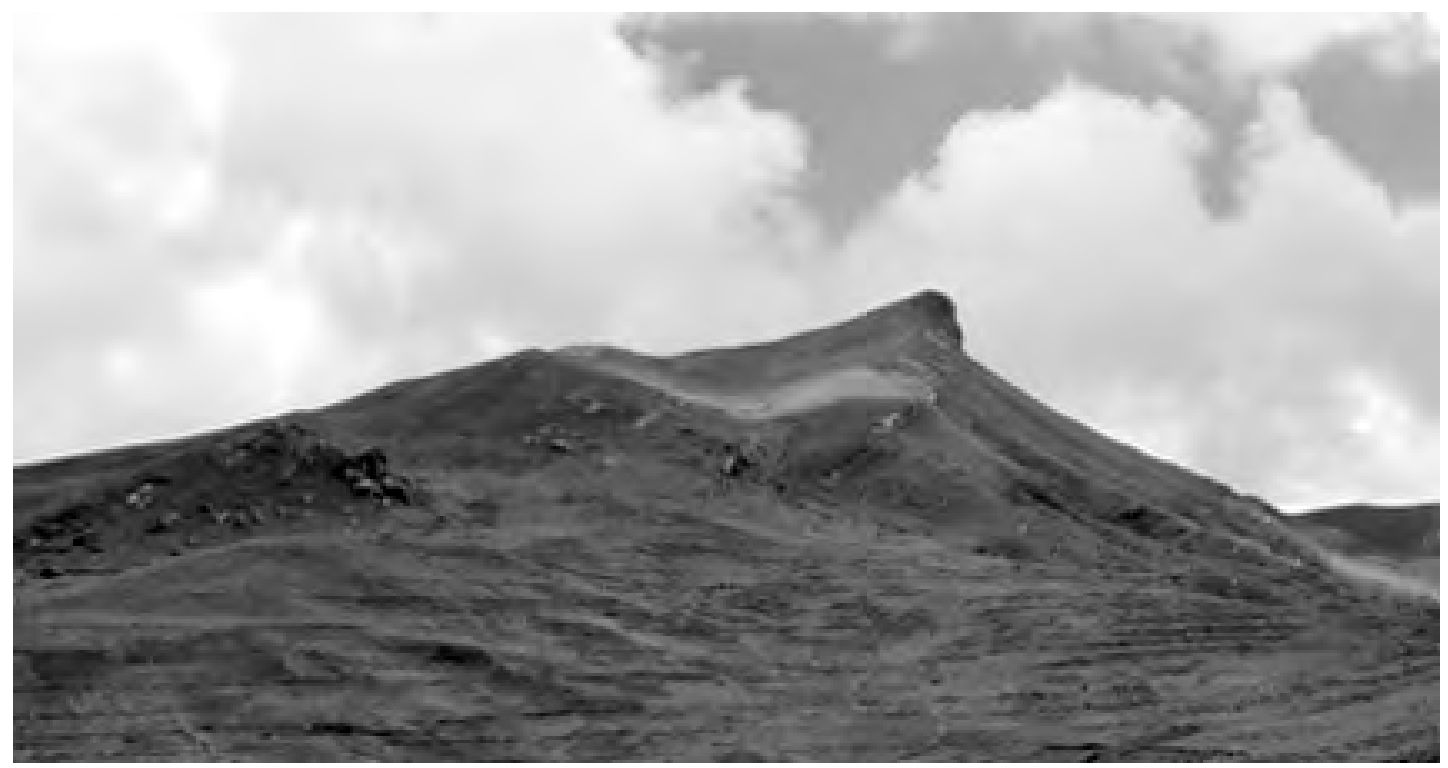

Figura 1: Panorámica desde la base del lado este, lográndose apreciar su configuración topográfica del Apu Mama Simona. (Foto Wilber Bolivar Yapura)

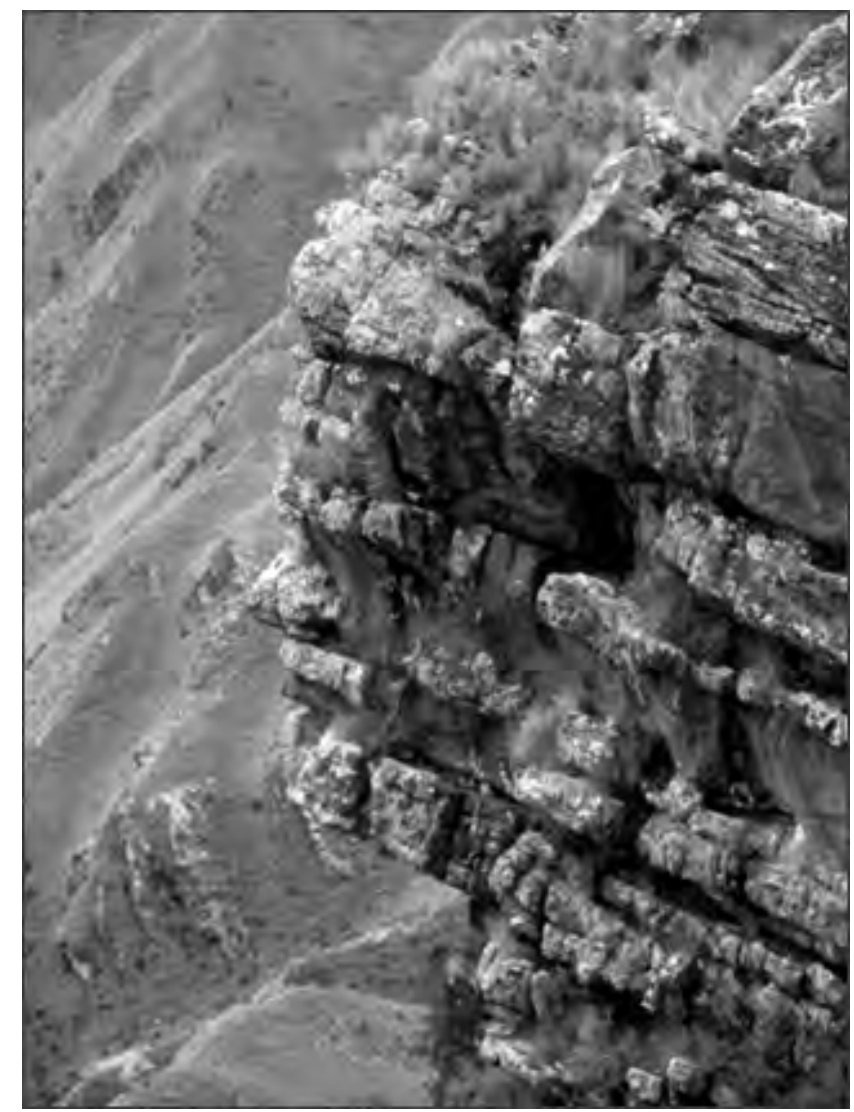

Figura 2: Acercamiento en la que se puede distinguir la geoforma, perfil facial de un rostro humano ideológicamente antropomorfisado). Foto Wilber Bolívar Yapura. 


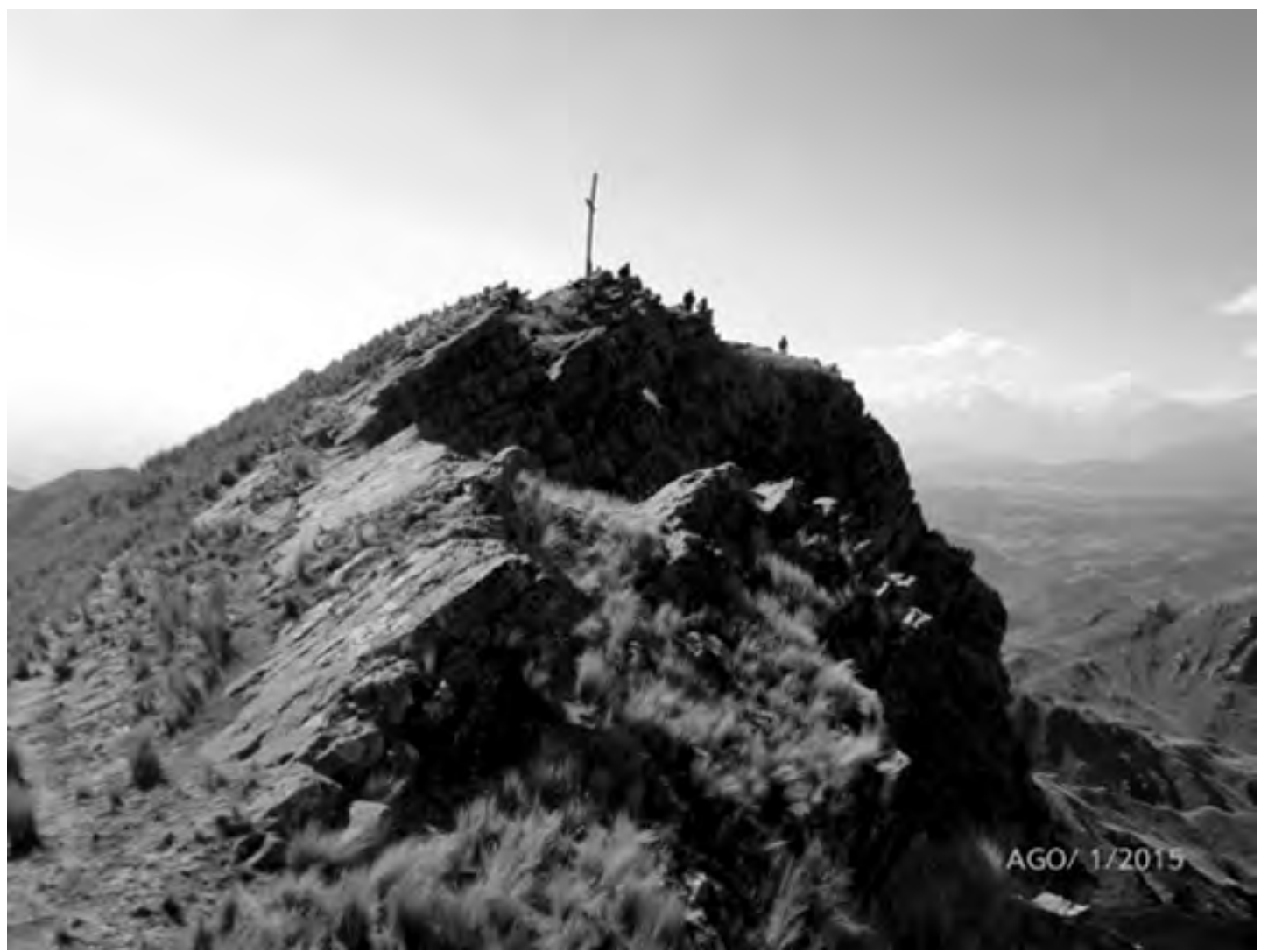

Figura 3: Vista del sector Cima

Salkantay, Humantay, La Verónica (Hucayhuilque), y la cordillera del Vilcabamba; luego en el valle del rio Vilcanota los nevados de Chicón; en Urubamba, Pitusiray y Sahuasiray en Calca; el Senqa, Saqsayhuaman, Pikol y Pachatusan en el valle del Cusco; Viracochan en Anadahuaylillas y el Ausangate al fondo, para finalmente terminar con el Huanacahure ${ }^{1}$. En la actualidad se continúan practicando ceremonias votivas consistente en pagos ceremoniales al Apu para pedir dadivas. Tiene una configuración topográfica irregular en cuyo espacio se registra una cruz impuesta por la religión Católica, que es venerada en el mes de mayo en la fiesta de las cruces.

Sector Estructuras: Emplazada hacia la parte baja del cerro Mama Simona, en la que se llegó a registrar una serie de estructuras irregulares y ovoides los cuales probablemente cumplieron la función de corrales. En la actualidad de todo este sector solo se llega a evidenciar algunas hileras de muros, los cuales tiene un ancho de 1.10 metros. En el lado suroeste se evidencia un corral el cual está adosado al afloramiento rocoso, presenta 2 a 3 hileras de material lítico y su tipo de aparejo es el Pirqado al seco, este muro mide 0.90 metros de ancho y una altura promedio 1.10 metros, tal como se puede apreciar en el registro fotográfico. personal. 


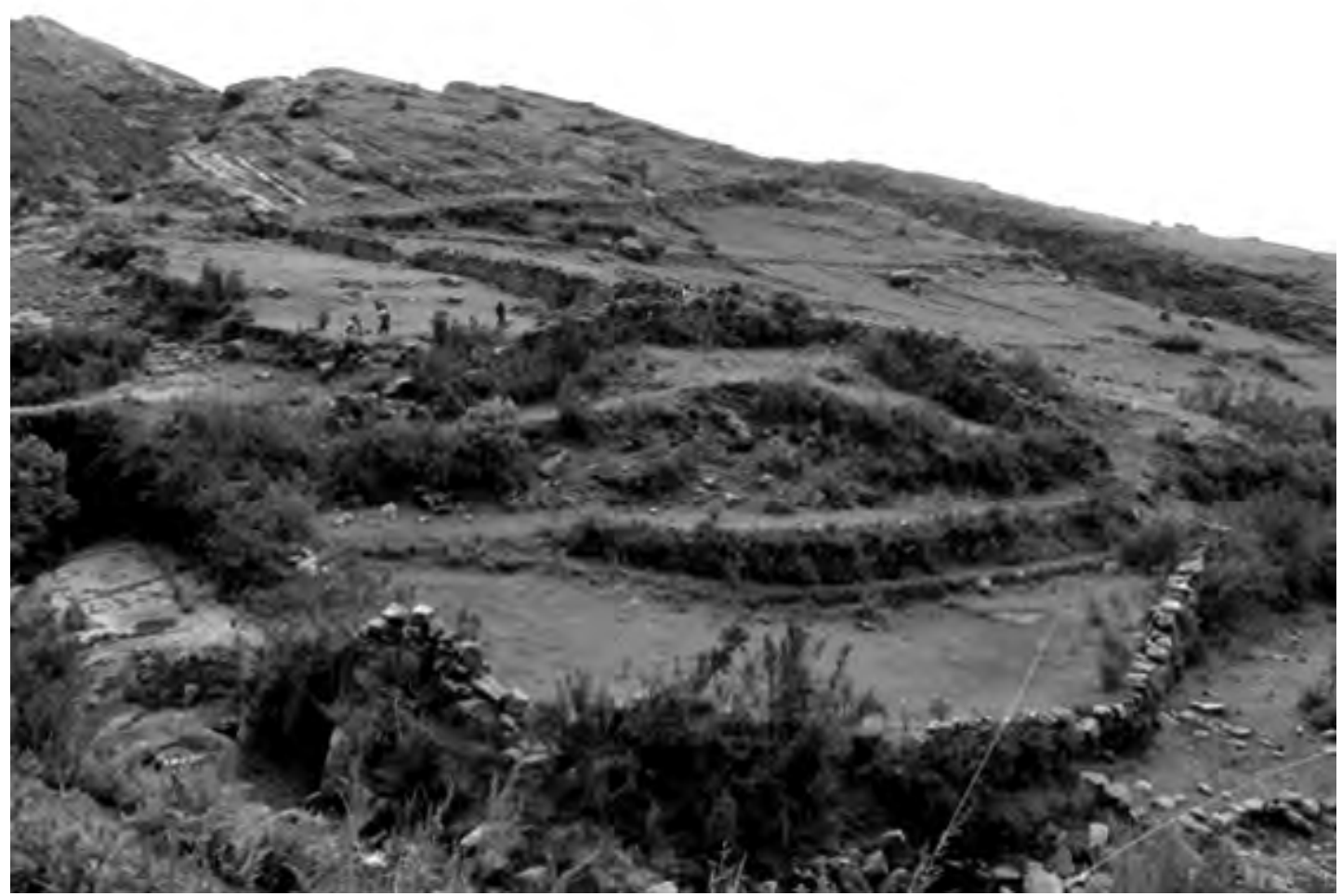

Figura 4: Área en la base del Apu con estructuras de canchas, pontones y recintos prehispánicos

Geomorfología: El relieve de la zona comprende, una topografía irregular con cumbres alineadas en dirección noroeste; las mismas que forman ligeras quebradas con un sistema de drenaje que corresponden a la zonificación local denominada montañas de Huilcaconga que se denomina así por la serie de cumbres alineadas, entre los que se tiene: el cerro Huilcaconga y otros (López y Vilches 1997:7).

El espacio estudiado se caracteriza por una diversidad de formas en la corteza terrestre; la parte suroeste del valle del Cusco presenta microbases que tienen una orientación de suroeste a noroeste; la división geomorfológica, está dada por el divortiun acuariun en las abras de Mama Simona, Hatun Punkuray, Oq'opata, Qoyllorpugio, Llaulliq'asa. El área en estudio en mayor porcentaje se encuentra dentro de la unidad fisiográfica regional denominado altiplanicie.

Las altiplanicies de nuestra región se caracterizan por presentar un relieve ligeramente plano o superficies planas elevadas en donde se levantan colinas bisectadas por valles relativamente profundos como el Apurímac y el Vilcanota desarrollándose, en algunos lugares, con sus fondos amplios que constituyen depresiones como Cusco y Yaurisque, etc.

El relieve de nuestro espacio de estudio es muy variado que va desde los 2,300 m.s.n.m. del valle del río Apurímac hasta los 4,300 m.s.n.m. en la localidad de Llaulliqasa, con pendientes que varían desde superficies ligeramente planas $5^{\circ}$ en las lomadas de Ocopata hasta las abruptas casi verticales de $85^{\circ}$ en las laderas de los valles y quebradas que drenan a los principales colectores de la zona en 


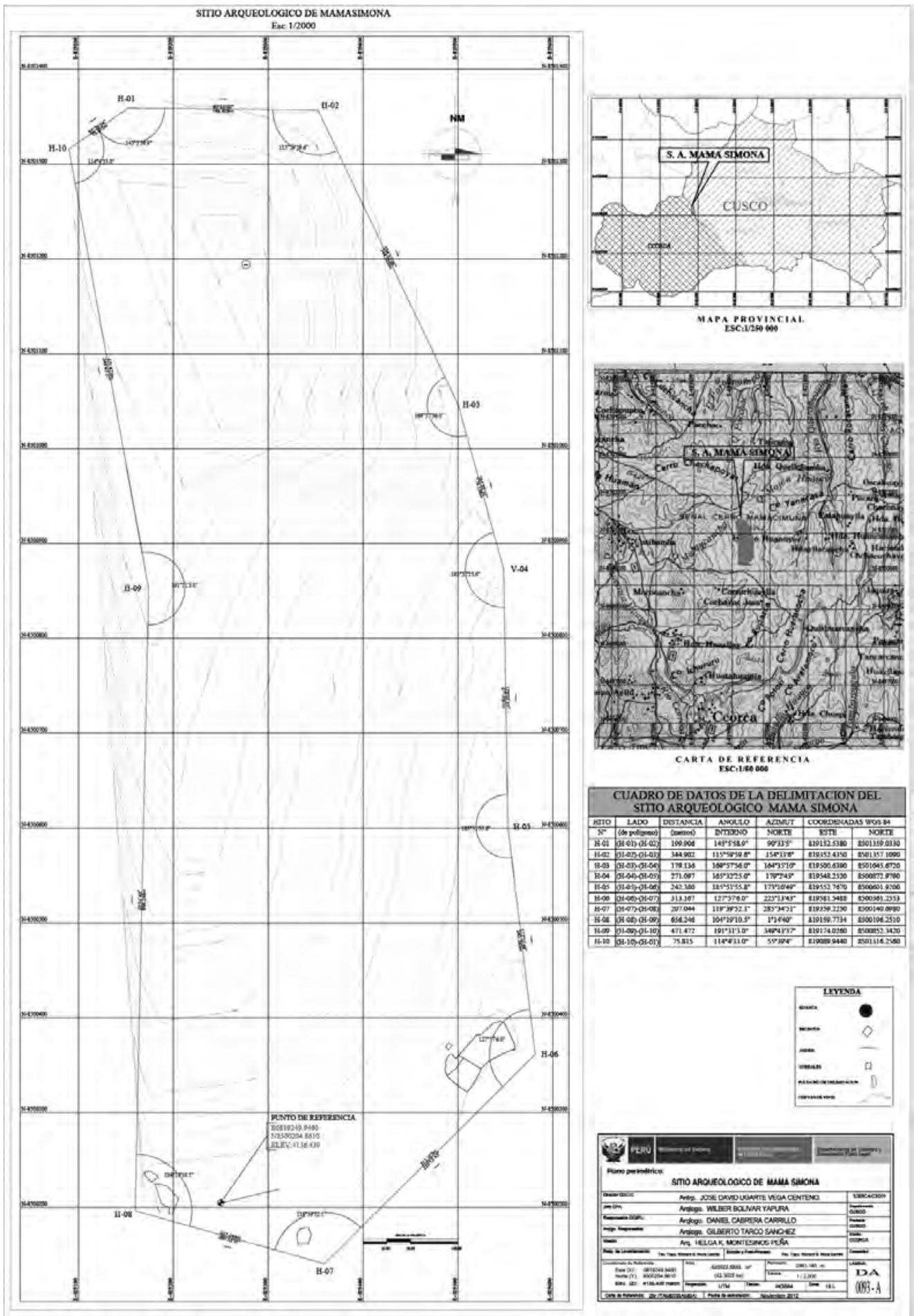


estudio, los cuales son: el río Huancaro en la sub cuenca del Cusco: los ríos Q'orqa, Yaurisque, Huanoquite, y Mollebamba, son tributarios del río Apurímac respectivamente.

En nuestro recorrido registramos varias montañas que forman la parte oeste del valle de Cusco; entre estas tenemos el cerro Picchu, con una elevación de 3960 m.s.n.m, Huamancharpa con 4105 metros, Mama Simona con 4136.439 m.s.n.m. controlados por el anticlinal de Picchu y Huanoquite a 4050 m.s.n.m.

\section{ANTECEDENTES ETNOHISTÓRICOS}

Polo de Ondegardo en capítulo que trata de los Ceques y Guacas del Camino al Contisuyo dice: "El camino de Cuntisuyu, que nosotros llamamos Condesuyo, tenia catorce Ceqves y ochenta Guacas,...El sexto Ceque deste mismo camino se llamaba Payan, y tenia cinco Guacas. La primera tenia por nombre Apian. Era una piedra de los Pururaucas que estaba en el sitio que hoy tiene Santo Domingo" (Polo de Ondegardo;1571/1917)

Sarmiento de Gamboa, en su crónica² dice:

"Por la mañana enviaban un carnero a Huanacauri, que es la huaca principal que ellos tienen como en la Historia de los Incas esta dicho, en donde le mataban y quemaban los tarpuntaes, que eran los que tenían cargo de dar de comer a las huacas, y mientras lo quemaban, al salir del Sol por la mañana, iban muchos incas y caciques arrancando la lana del dicho carnero. Antes que le quemasen andaban dando voces alrededor del sacrificio con la lana en las manos, diciendo: "Oh Hacedor, Sol y Trueno, sed siempre mozos y multipliquen las gentes y estén siempre en paz". Y a mediodía, por la misma orden, quemaban otro carnero en Qorikancha en el patio de la dicha casa del Sol, que ahora es claustro de los frailes del señor Santo Domingo; y al entrar del Sol llevaban otro al cerro llamado Aspiran, porque sobre él se pone el Sol, el cual sacrificaban por la misma orden. Sacrificaban demás desto y ofrecian a las dichas huacas, unos cestillos de coca llamados paucaruncu y unos que llamaban paucarquintu, a manera de coca, y un poco de maíz tostado y conchas de la mar, que llaman mullo, colorado y amarillo, hechas a manera de maíz. El Collasuyo, que está al nacimiento del Sol, y al poniente, que es el camino de Chinchaysuyo". (Sarmiento Gamboa; 1572/1965)

Luego cuando Gamboa, se refiere a Pachacuti Inga Yupangui Inga en el Cap. (31) dice que "reedifica la casa del Sol y establece nuevos ídolos en ella" y en otro acápite manifiesta lo siguiente: "Habia demas de esta casa, a la redonda del pueblo, algunas guacas, que eran la de Guanacauri y otra llamada Anaguarqui y otra llamada Yauira y otra dicha Cinga y otra Picol y otra que se llamaba Pachatopan, en muchas de las cuales se hacían los malditos sacrificios, que ellos llaman capac cocha, que es enterrar vivos unos niños de cinco o seis años ofrecidos al diablo con mucho servicio y vasijas de oro y plata"3.

Cristóbal de Molina (el cusqueño); indica en su crónica "Ritos fabulas de los incas”: “... y a medio día, por la misma orden, queman otro carnero en Qorikancha en el patio de dicha casa del sol, que ahora es claustro de los frailes del señor Santo Domingo; y al entrar el sol llevaban otro al cerro llamado Aspiran, porque sobre él se pone el sol el cual sacrificaban por la misma orden..." (Molina, 1573/1947).

Bernabé Cobo, en el Cap. XV dice lo siguiente: "De los ceques y guacas del camino de Cuntisuyu. El camino de Cuntisuyu, que nosotros llamamos Condesuyo, tenia catorce ceques y ochenta guacas,...El sexto ceque deste mismo camino se llamaba Payan, y tenia cinco guacas. La primera tenia por nombre Apian. Era una piedra de los pururaucas que estaba en el sitio que hoy tiene Santo Domingo". (Cobo; 1653/1964)

2. Cap. VI - Cultos, Sacrificios y Festividades Mayo de Sarmiento de Gamboa.

3. En: Sarmiento de Gamboa, Pedro.1572/1965 Historia de los Incas. 
En el inédito de Cristóbal de Albornoz ${ }^{4}$ dice: "Yauirac, que eran muchas piedras juntas. Hazian muchos sacrificios en ellas de indios".

\section{INVESTIGACIONES RELACIONADAS CON EL TEMA}

Es muy probable que dentro de la ideología prehispánica (Intermedio Tardío), el culto a los Apus, como Apian, Aspiran y Yauira, de nuevo Aspiran, otra vez Apian y Yauirac ${ }^{5}$. Denominado hoy como Mama Simona, fuese considerado como un espacio sagrado en la realización de ceremonias como el Qhapaq Qocha, y el Haywarikuy se realizaban solo en lugares que tenían una debida importancia, además que las construcciones que se observan en la base de esta montaña ratifican su condición, y porque desde su cumbre se puede apreciar otras montañas y Apus que no solo rodean el valle del Cusco sino también el Salkantay, Humantay, Verónica, Chicón, y el Ausangate, más allá de las fronteras del valle del cusco.

Reinhard en sus investigaciones, sobre santuarios de altura, refiere que los lugares con construcciones prehispánicas en las montañas andinas generalmente están conformados por estructuras simbólicas, plataformas artificiales y estructuras para protegerse de los elementos naturales (como lluvia, viento, nieve), también hallándose ofrendas rituales de coca, estatuillas, tejidos y algunas veces hasta sacrificios humanos. (Reinhard 1983:28)

Miguel Cornejo cuando sintetiza sobre santuarios de altura sostiene que la presencia de estos "Santuarios de altura" está enmarcada en un ordenamiento espacial incaico que conocemos parcialmente y que obedece a su forma de entender el mundo, estos santuarios no se encontraban en cualquier lugar ubicándose de acuerdo al interés del Cusco y a los sitios ceremoniales que servían para la integración de los pueblos incorporados al sistema Incaico (Cornejo 1995:64)

Ceruti concluye que los Santuarios de altura frecuentemente cuentan con estructuras arquitectónicas de tamaño estandarizado, delimitando espacios segregados, así las plataformas sobre elevadas delimitan un espacio elevado en relación al santuario separando a los oficiantes de los asistentes al culto (Ceruti 1999:35).

Por ejemplo en la interpretación que realizan sobre el cerro Pachatusan Cori y Baca, manifiestan lo siguiente:

"El cerro Pachatusan considerado por los pobladores cercanos al lugar como "Apu", al cual se le invoca para pedir protección y producción; geomorfológicamente es diferente a los otros cerros, que rodean el valle del Cusco; su mayor altitud hace que se concentre gran cantidad de nubes en su cima, procurando mayor humedad que se evidencia en la presencia de manantiales que posee tanto hacia el valle del Cusco, como hacia el Vilcanota...” (Cori y Baca. 2004. Pág. 183)

Por la sistematización y análisis de datos al perecer Mama Simona fue un espacio ceremonial construido ideológicamente, donde se realizaban ceremonias rituales a una deidad con espíritu femenino, por otro lado Constanza Ceruti, denomina "Santuarios de altura" a los sitios arqueológicos con características similares a Mama Simona, pero ubicados en alturas superiores a 5,000 m.s.n.m.;

4. La Instrucción para descubrir todas la Guacas del Piru sus camayos y Haziendas En el inédito de Cristóbal de Albornoz, eclesiástico de la diócesis del Cuzco, no tiene fecha, pero por la condición del papel y por el carácter de la letra, se redactó indudablemente a fines del siglo décimo sexto.

5. Apian (Polo de Ondegardo), Aspiran y Yauira (Sarmiento de Gamboa), Aspiran (Cristóbal de Molina el cusqueño), Apian (Bernabé Cobo) y Yauirac (Inédito de Cristóbal de Albornoz) 
sin embargo alrededor del valle del Cusco no se tiene cerros con mayor altura que el Pachatusan, con 4,842 m.s.n.m.; Huanacaure, Picol, Senqa y Mama Simona, por lo que es uno de los cerros más alto con estructuras Inka pudiendo considerarse dentro de la denominación de Santuario de media altura.

En un trabajo inédito que esta por publicarse el Antropólogo. Luis Negrón Alonso, amablemente me ofreció su material de trabajo denominado Qusqupa Seqénkuna, Wakankuna (Los Seques y Wakas del Cusco), el mismo que está referido a la relación de adoratorios anoticiados por los cronistas del siglo XVI, entre ellos Polo de Ondegardo, el cusqueño Molina, testimoniados por Bernabé Cobo; son lugares sagrados que estaban inscritos en el paisaje inmediato a la capital del Tawantinsuyo: Qusqu, hoy la ciudad del Cusco.

Nos ofrece un guia que presenta de manera desagregada, el nombre de Siq'i, (Seque) su ubicación, el nombre de la Waka, su forma y material, el tipo de ofrenda, y el motivo de su existencia. Además intenta dar pistas respecto al significado de sus nombres en lengua quechua, y una aproximada traducción al castellano y utiliza como fuente la relación de las Waka codificadas por Rowe ${ }^{6}$, el mismo que se traduce en los siguientes cuadros.

\begin{tabular}{|c|c|c|c|c|c|c|c|}
\hline \multicolumn{8}{|c|}{ QUSQUPA (TAWANTINSUYUPA) SIQTNKUNA, WAK ANKUNA DEL CHINCHAYSUYO } \\
\hline SIQT & CODIGO & WAK'A & UBICACION & $\begin{array}{l}\text { iQUE ES- } \\
\text { SON }\end{array}$ & FORMA & OFRENDA & MOTIVO \\
\hline CAPAC & Ch. $9: 6$ & Upuvauira & En cerro Piccho & $\begin{array}{l}\text { Una } \\
\text { Piedra }\end{array}$ & Hombre & ? & $\begin{array}{l}\text { Que era uno de los } \\
\text { que salieron de la } \\
\text { tierra con } \\
\text { Huanacauri. } \\
\text { Adoraban todos los } \\
\text { ayllus en el fiesta } \\
\text { del Ravmi }\end{array}$ \\
\hline \multicolumn{8}{|c|}{ QUSQUPA (TAWANTINSUYUPA) SIQ TNKUNA, WAK ANKUNA DEL CONTISUYO } \\
\hline PAYAN & $\mathrm{Cu}-6: 1$ & Apian & $\begin{array}{c}\text { En el sitio de } \\
\text { Santo Domingo }\end{array}$ & $\begin{array}{l}\text { Una } \\
\text { Piedra }\end{array}$ & Redonda & ? & De los Pururaucas \\
\hline
\end{tabular}

\begin{tabular}{|c|c|c|c|c|c|}
\hline \multicolumn{6}{|c|}{$\begin{array}{l}\text { QUSQUPA, SEQ'ENKUNA, WAK'ANKUNA SUTIYASPAN } \\
\text { (NOMBRES DE LOS SEQUES Y HUCAS DEL CUSCO) }\end{array}$} \\
\hline SIQ'I & CÓDIGO & $\begin{array}{l}\text { MONBRE } \\
\text { WAKA }\end{array}$ & $\begin{array}{c}\text { QUECHUA } \\
\text { CUSCO } \\
\text { COLLAO } \\
\text { (A) AYMARA }\end{array}$ & $\begin{array}{l}\text { POSIBLES OPCIONES } \\
\text { DE TRADUCCIÓN }\end{array}$ & MOTIVO \\
\hline $\begin{array}{l}\text { Ch-9:0 } \\
\text { Capac }\end{array}$ & Ch-9:6 & Apuyauria & Apu yarirag & $\begin{array}{c}\text { Apu=señor grande, } \\
\text { poderoso, excelso, dios. } \\
\text { Yariraq=antes }\end{array}$ & $\begin{array}{l}\text { Que era uno de los que } \\
\text { salieron de la tierra con } \\
\text { Huanacauri Adoraban } \\
\text { todos los ayllos en la } \\
\text { fiesta del Raymi }\end{array}$ \\
\hline $\begin{array}{l}\text { Ch-0:0 } \\
\text { Payan }\end{array}$ & $\mathrm{Cu}-\&: 1$ & Apian & & & \\
\hline
\end{tabular}

Cuadros elaborados en base al esquema ofrecido por el Antropólogo Luis Negrón Alonso (2015)

6. Qusqupa Seqénkuna, Wakankuna (Los Seques y Wakas del Cusco) Inédito de Luis Negrón Alonso 2015 


\section{Los Apus en el SISTEMA de WAK'As.}

Hoy por hoy con las recientes investigaciones sabemos que las montañas hechas deidades, integraban la larga lista de Wak'as que eran objeto de reverencia o culto en el mundo prehispánico a la llegada de los españoles. La información del siglo XVI registra la denominación Apu para referirse a importantes Wak'as/Apu. Algunas Wak'as principales eran conocidas como Apus. Tal el caso de la Wak'a Aporima que fue un oráculo principal reconocido por los Inkas (Pizarro [1572] 1978: 81-83).

En la relación de Wak'as principales presentada por Albornoz, aparecen entre otras, las Wak'as Aporimac, una piedra a manera de indio; Aputinya, una piedra en un cerro encima del actual pueblo de Amaybamba (Cuzco), considerado dueño de la coca (Pérez Bocanegra 1631: 155, 88).

El uso del término Apu para designar a los ancestros deidificados estaba bastante difundido en lo que fue el territorio del antiguo Perú. Era frecuente además que los vocablos Waman y Apu se acompañasen, indicando la posición predominante de una divinidad entre otras similares. Estas anotaciones y otras observaciones que no han de tardar en aparecer irán demostrando con seguridad la antigüedad de la denominación Apu para identificar a las Wak’as y/o montañas.

Para nuestro caso la montaña denominada como Mama Simona, reconocida como Apu femenino está claramente explicado en los cuadros 1 y 2 del sistema de Wak'as y Ceques del Cuzco, que proponemos en base al trabajo del antropólogo Luis Negrón Alonso.

Por lo tanto es fundamental el sistema de Ceques para el conocimiento de la organización del estado Inca, porque estas cumplían funciones de orden político, Social y Religioso. Consistían en líneas imaginarias que partían desde el Coricancha hacia cada Wak'a, constituido por un total de 328.

“...es importante reconocer que el sistema de Ceques, paralelo físico (y presumiblemente cultural) más cercano a los cerros radiales, incluía entre sus múltiples funciones tanto la provisión de agua como las orientaciones astronómicas... El sistema de Ceques...era un dispositivo mnemónico construido sobre la topografía natural y artificial del Cuzco, con el fin de unificar la organización religiosa, social y política de los incas, así como la administración del agua, el calendario y la astronomía. Esta se componía de un número de líneas imaginarias (Ceques) producidas por la alineación de Wak'as (sitios sagrados). Estos salían en direcciones intercardinales del Coricancha que se halla en la confluencia de los ríos Choquechaca y Saphy, los cuales estaban agrupados por zonas de acuerdo con su ubicación dentro de cada una de las cuatro partes o Suyos del Cuzco." (Negrón Alonso; 2015)

Los principales atributos de las montañas se identifican a través de las siguientes condiciones, las cuales cumple Mama Simona, además la captación de la atención está representado por ser una alta montaña que sobresale, pudiéndose divisarse desde varios puntos como Chinchero, Saqsayhuaman, Picol, Huaccoto y Huanacaure, que a su vez es considerada como una diosa protectora del hombre, de las plantas, animales, elementos físicos y atmosféricos de su entorno.

Son fuentes de vida e inducen la reproducción: Por ser lugares de origen o Paqarinas de las gentes y animales; estos pueden identificarse a través de grietas en las montañas, manantiales, lagunas y otros accidentes topográficos de su entorno vistos como puertas que comunican con el mundo interior y entendido en el mudo andino prehispánico, ejemplo el surgimiento de los hombres se produce a través de las paqarinas (cuevas y lagunas) ubicadas en lugares de origen como el nevado Awsangate y el Salkantay.

Esta presencia de la divinidad es considerada como el Apu de la fertilidad (Pachamama), dentro del sistema de seques T. Zuidema (1995) la menciona como una Saywa de carácter religioso y para la actualidad las poblaciones de Ccorca y Poroy la considera un oráculo de predicción para la buena productividad de diferentes tubérculos durante el año. 
Son Protectores y sanadores: Otro de los atributos más significativos de las deidades montaña es su poder sanador y protector contra las enfermedades. Para la gente de los Andes, la mejoría y bienestar de los hombres e incluso del ganado proviene de las acciones de los Apus. Se puede entrar en comunicación con las deidades tutelares mediante el sueño o en sesiones de consulta con la intervención de especialistas (paq'os, alto misayoqs varones o mujeres)

Si las personas quieren protegerse incluyendo sus ganados deben ofrecer ofrendas para alimentar a las deidades, si estas no son del agrado de la deidad o Apu, la persona puede caer en dolencias o sobrevenir la mortandad del ganado por enfermedades inexplicables o por ataque de sus depredadores. Por eso los especialistas deben traducir al final de la quema de la ofrenda o de la t'inka (aspersión ceremonial), si el Apu recibió con agrado la ofrenda. Por ejemplo si se ve pasar volando a un halcón o águila significa que lo ofrenda fue recibida con agrado y que como respuesta se tendrá lo solicitado.

El testimonio de José Huamani de 63 años poblador de Ccorca dice: "varias personas que suben al Apu Mama Simona van con fe, hacen previos pagos a la tierra para subir al Apu y piden por la salud de sus familias, dinero, trabajo, estudios, etc.". Por otro lado nos cuenta la historia de un estadounidense quien cada domingo acudía donde Mama Simona, ofreciéndole pagos pidiéndole por la salud de su mamá que padecía de cáncer, después de 6 meses de constantes visitas al Apu, su madre sano repentinamente y los médicos no podían explicar la curación" "

Sánchez Garrafa, anota en su publicación lo siguiente: "Las personas enfermas mandan que sus hijos y parientes vayan hasta los lugares de ofrenda en la montaña y hagan sacrificios en su nombre. ofrecen "pagos" (ofrendas complejas) a sus montañas tutelares, demandando que las ayuden a liberarse de las enfermedades e intercedan ante la tierra u otros seres que pudieron haberse apoderado de sus sombras o ánimo". (Sánchez Garrafa; 2015)

Otorgan y distribuyen el agua: Así como el Salkantay que es una alta montaña, estos tienen la capacidad de atraer o detener las nubes en sus cimas, los relatos míticos consideran que las montañas, por dentro, están llenas de agua. Por lo tanto, a la montaña y a los seres que viven ahí se les atribuye poder para dotar de agua a los seres con vida y son garantes del uso del agua, que al unirse propician la reproducción de las especies.

En esta concepción, los cerros (Mama Simona), plantas y animales se hallan hermanados por compartir un mismo impulso vital, tal como indican los campesinos de $Q^{\prime} e^{8}{ }^{8}$, Cusco “... de la tierra nacemos todos, ella nos cría y nos amamanta, es la madre tierra..."

No es extraño, dentro de esta concepción decir, por ejemplo, que "el agua camina", "la semilla se acostumbra", "la papa se enseña", "el cerro se resiente", "esta semilla es nuestra nuera", "la semilla está cansada", etc. Estas expresiones explican muy bien el carácter de las relaciones entre sociedad y naturaleza, y el cariño y comprensión con que se relacionan hombres y naturaleza.

Para corroborar el atributo dador de agua desde el Formativo, las excavaciones arqueológicas en la cuenca del rio Vilcanota han ido revelando restos de patios hundidos como vestigios de un sistema ideológico religioso, en el cual los cerros sagrados fueron sus puntos de conexión allá por el período Formativo, como parte de un mapa geográfico cognitivo compartido en áreas geográficas regionales bastante amplias (Zapata 1998: 307).

En las dos últimas décadas se ha confirmado la existencia de adoratorios y enterramientos prehispánicos en muchas de las altas montañas de los Andes, particularmente en nevados y volcanes

7. Testimonios recogidos en trabajo de campo. Agosto del 2014 en el haywaricuy y peregrinación a la montaña Mama Simona.

8. Notas referenciales de paq'os especialistas de Q'ero que llegan al Cusco como oficiantes de pagos u ofrendas a los Apus en el mes de agosto. 
como el Misti, Pichupichu, Sarasara, Qhoropuna. En estos espacios sagrados que se ubican sobre los $3400 \mathrm{msnm}$, se procesaron oblaciones a las divinidades tutelares y ancestros por medio de rituales complejos donde se incineraban ofrendas; importancia ceremonial que se hace manifiesta en las modificaciones introducidas con la construcción de terrazas, templos, altares y estructuras funerarias.

Siendo la montaña una especie de morada de los ancestros deidificados, era frecuente que el ancestro propiamente dicho fuese representado por un ídolo de piedra, madera o por un ceramio de apariencia antropomorfa que era vestido de manera galana y fina. Las representaciones pétreas eran llamadas Wankas. (Sánchez Garrafa; 2015)

Por ejemplo, Cobo dice "De los ceques y guacas del camino de Cuntisuyu. El camino de Cuntisuyu, que nosotros llamamos Condesuyo, tenia catorce ceques y ochenta guacas,...El sexto ceque deste mismo camino se llamaba Payan, y tenia cinco guacas. La primera tenia por nombre Apian. Era una piedra de los pururaucas que estaba en el sitio que hoy tiene Santo Domingo". (Cobo; 1653/1964)

Mama Simona en nuestros días: Según Sánchez, hay que proponer respuestas plausibles a las interrogantes pendientes respecto a: i) La existencia o no de una categoría semántica llamada Apu, y ii) La profundidad del enraizamiento de esta categoría en el pensamiento andino prehispánico.

En lo concerniente a la relación entre los Apus actuales y las antiguas Wak'as a que hacen referencia las crónicas de los siglos XVI y XVII, se ha sugerido que los Apus son posteriores a la transformación de las Wak'as en los santos locales, como secuela de un proceso de evangelización en el que el multiteísmo andino habría aceptado al dios cristiano sin modificar su esencia politeísta. Los Apus son deidades locales o regionales no necesariamente dependientes de la antigua religión del incario y que subsisten con autonomía respecto a la cosmovisión cristiana. (Sánchez Garrafa; 2015).

Las creencias hacen que la actividad social y política se vea influenciada por supersticiones, por lo que se mantienen vigentes hasta la actualidad, claro ejemplo son las evidencias arqueológicas consistentes en pinturas rupestres, fragmentos de cerámica prehispánica, restos óseos (sacrificios) y el Qhapaqñan hacia el Contisuyo (ruta del pescado) que atraviesan el distrito de Ccorca. En cuanto a la Arqueología de Culto y Religión nos muestra todas las creencias del ser humano tanto individuales como colectivas, y es por lo tanto en realidad considerablemente compleja. Insoll, ${ }^{9}$ nos menciona que la arqueología del culto y religión se basa en cuatro indicadores: i) La captación de la atención. ii) La zona fronteriza de este mundo. iii) La presencia de la divinidad y iv) La participación y las ofrendas.

\section{La participación y las ofrendas:}

Antes: Las fiestas de cada mes del año en la época prehispánica tuvieron cierta importancia; el noveno mes se llamaba yapaquis en el cual se quemaba otros cien carneros castaños y se degollaban y quemaban mil cuyes para que el hielo, el aire, el agua y el sol no dañasen a las chacras. Este ritual pertenece al mes de agosto. (Valcárcel 1978)

En la actualidad: Con mayor frecuencia el primer día de agosto y durante el mes, los Paqos y Altomisayoq (curanderos) acuden a la cima del Apu Mama Simona a realizar sus ofrendas y despachos de pago a la Pachamama y el Apu pidiendo hijos, es sabido que Mama Simona es madre dadora de hijos.

La parentela sagrada de las montañas: Sánchez, propone que los relatos míticos evidencian la existencia de linajes divinizados vinculados míticamente a un progenitor padre-abuelo-viejo, en 
torno al cual se organiza una corte de descendientes varones y mujeres, así como otros parientes afines. Las relaciones de parentesco entre deidades, y entre éstas y los hombres, suelen justificar intercambios sociales, otorgamiento de dones y contra dones, y participación dentro de sistemas de irrigación regulados. Estos patrones ideales de interacción social refrendan las bases de reciprocidad. Los intercambios establecidos por los dioses fundamentan la práctica social en espacios discretos a mediana y larga distancia. Las genealogías míticas que enfatizan paradigmas incólumes del pasado se actualizan permanentemente en el orden de la sociedad humana. Los hombres y mujeres del presente se reconocen en los actos, deseos y requerimientos de sus divinidades. Por un lado, se reconoce que las propias deidades están vinculadas entre sí por relaciones de parentesco, en torno al Apu considerado más poderoso; de otro, entre las deidades y los especialistas mediadores suele establecerse también un parentesco simbólico. (Sánchez Garrafa; 2015)

Por otro lado son raros los Apus femeninos en las cercanías del valle del Cusco. Mama Simona, es quizás la montaña con espíritu femenino y con parentela sagrada, sin embargo no es la única y son las que tienen esposos o están emparentadas con otras montañas masculinas, como por ejemplo la montaña de Huacay Huillca (también denominada con los nombres de Waqaywillca o Verónica (5750 m.s.n.m.), denominada China Salkantay (en quechua significa mujer). Como esposa y mujer del Salkantay. Al respecto se puede anotar lo siguiente:

"Los apus de Salkantay y Ausangate son iguales (masintin) como hermanos, cada uno tiene su familia, la esposa del Apu Salkantay es la Verónica (Waqaywillca) sus hijos son el (Humantay ó Tukarhuay) hijo menor y (Yanantay ó Coyllur) hija menor, sus rebaños son los luichos, tarukas, vizcachas, poronqoe etc, etc, cuando el Salkantay está molesto por algo malo que hacen sus súbditos, empieza a rugir y botar nieve (desprendimientos de hielo de su cima" (Bolívar 2015: 158). ${ }^{10}$

Los apus Salkantay, Humantay son las dos más poderosas deidades del lugar, el primero está protegido por tres personajes del sexo masculino, los que son los encargados de racionar y distribuir el agua que baja de sus nieves perpetuas, castiga a los que faltan a las leyes impuestas por ellos y también la fertilidad de los ganados y de las tierras. ${ }^{11}$

Dentro de la comunidad local se sigue respetando a los dioses tutelares, la tradición oral que se viene repitiendo de generación en generación, desde épocas tempranas, indican que en el caso especial del culto al agua, se viene repitiendo mucho de los elementales ritos y ceremonias, que se llevan en fechas especiales para pedir a ellos ayuda en las actividades cotidianas de la población.

También se tiene otra referencia sobre este tema el de (Espinoza; 2004) que dice lo siguiente:

"El Apu Auzangate fue considerado por sus adversarios como el más poderoso, tenía mucha fortuna en oro, en plata y rebaños de llamas, alpacas blancas. Vivía acompañado de su esposa "Cayancate" que es diosa de las alpacas de color. Se encuentra ubicado a un extremo de la laguna de "Singrina qocha" que tiene un color esmeralda, a esta laguna se ofrendada cada 10 de agosto por los pastores de Yanakancha; ellos creen que de los manantes existentes en las zonas, salen alpacas que en algunos casos son capturados por los que tienen suerte, pero que en sus manos se convierten en Enqaychus o Illas (objeto mágico zoomórfico), que son guardados como objetos mágicos dentro del "messa q'epe" (parafemalia pastoril o atado ritual).

10. Comunicación personal Nicasio Ttito Huaman C.C. Pampaq'amara- distrito de Ccatq'a provincia de Paucartambo (82 años). En cambio en el Paisaje Cultural de la Montaña del Salkantay y su Impacto en las Ideologías locales. El caso de Soraypampa (prov. de Anta, región del Cusco).

11. Simone Apostolo, lo Zelote; Frances. Simón le Zélote ou le Cananéen; Simon the Zealot: alem. Simón Zelotes. apostol. Siglo I. Fiesta: el 28 de octubre. 
Se dice que tenían dos hijas llamadas "María Saqapana" y "Juana Huamanticlla", que son diosas. "María Saqapana" es diosa de la papa dulce, y "Juana Huamanticlla" diosa de la papa amarga.

Según el "paqo" (sacerdote Andino) Hermenegildo Condori, las hijas de Auzangate están representadas por dos cerros gemelas pequeñas, y están ubicadas al frente del nevado hacia Cusco, aparentando ser cuidadas celosamente por su padre. (Espinoza; 2004) ${ }^{12}$

“... a mí se me señalo con la caída de un trueno sobre mi cabeza y mi iniciación fue en Singrina qocha (una de la lagunas formadas por el deshielo del Ausangate), por eso yo pertenezco como paqo a la montaña de Ausangate. (Ttito Huaman;)"13

Estos diálogos nos confirman la existencia de relaciones de las montañas femeninas con los Apus masculinos. Para deslindar la parentela de Mama Simona, hay que manifestar que esta montaña, es el límite entre los distritos el de Ccorca y Poroy, los primeros asienten que la pareja de esta montaña es el Apu Machu Quimon (al parecer una forma adulterada del español al quechua), aunque podría tratarse del primer nombre católico asignado a la montaña como Simón, por la iglesia católica, el mismo que cambiaría más tarde a otro y los de Poroy manifiestan que es el Huayna Qorqor (joven roncador) lugar en donde caen con mucha más profusión los rayos, en temporadas de lluvia.

Según versiones del paq'o Isaac Huanca, ${ }^{14}$ quien manifiesta lo siguiente:

"Los auquis es igual que los hombres, ellos también tienes su parejas y su familia, y Mama Simona tiene como su esposo al auqui Machu Quimon, pero frecuentemente se peleaban y en una de esas peleas Mama Simona decide conseguirse un amante y ese era el Uña Quimon, enterado de esto Machu Kimon en un puñete le bajo una parte de la cabeza a Mama Simona. Por eso hoy en día ella tiene la cabeza partida. Además ella tiene como esposo al auqui Machu Quimon, con quien tuvieron un hijo que actualmente aparece cargando en la espalda". (Huanca 2011)

El testimonio del poblador Domingo Ccahuana, natural de Ccorqa que dice: "Salkantay y Ausangate estaban peleando por Mama Simona y ellos traían oro y plata en venados como haciendo pasar por burros al Apu Mama Simona , pero ella no quiso a ninguno de ellos y se quedó con el Apu Machuquimon por eso es que hoy Machuquimon está encima de Mama Simona" (Chávez 2011)15

Fernando Chávez Ccahuana, manifiesta lo siguiente: "Lo que me conto mi abuelito que el apu Salkantay y Ausangate son sus esposos y guardianes, pero Mama Simona no quería que se peleen entre apus y por eso se ha venido al medio" (Chávez 2012)

El testimonio de Dionisio Quispe manifiesta lo siguiente: "Todos conocen a Mama Simona pero no todos conocen su historia... el nombre de Mama Simona no lo pusieron las personas antiguas que vivieron ahí, sino que entre sueños los cerros avisan su nombre a las personas que van a pastear sus ganados y a recoger leña" (Quispe 2013) $)^{17}$

Josefina Salón, refiere que:

"hace muchos años por agosto a mi esposo le habían robado sus animales y el hizo un pago a la tierra en el cerro Quimon, diciendo Quimon muéstrame a mis animales y diciendo esto se quedó dormido; en sus sueños una voz le dijo: señor, señor levántese me está confundiendo. Quimon,

12. Artículo de Héctor Espinoza Martínez "El Joven Akanaku y las hijas del Apu Auzangate” En Oropesa: Revista y Sociedad Local No 50 de Julio del 2004.

13. Comunicación personal Nicasio Ttito Huaman C.C. Pampaq'amara- distrito de Ccatq'a provincia de Paucartambo (82 años).

14. Comunicación personal paq'o Isaac Huanca Berrios, 54 años (2011) Versión de Ccorca.

15. Comunicación personal de Domingo Ccahuana de 61 años, natural de Ccorca 2011

16. Comunicación personal Fernando Chávez Ccahuana, de 58 años, natural de Ccorca 2012

17. Comunicación personal de Dionisio Quispe, natural de Ccorca de 78 años, 2013 
Quimon yo no soy Quimon yo soy Simona si quieres pedirme o saludarme, llámame como Mama Simona, una semana después encontró a sus animales bien flacos, hay temporadas en que los abigeos roban ganados a los pastores ellos van hacer pago a Mama Simona para que le devuelvan su ganado y se cumplen sus deseos" (Salon 2013) ${ }^{18}$

Pastora de Huancabamba ${ }^{19}$ :

"El nombre de Mama Simona siempre ha sido así, desde que he escuchado los cuentos de mis abuelos, menciona que el Apu Mama Simona con el Apu Waynaccorco son marido y mujer. Se dice también que Waynaccorco para conquistar a mama Simona le mandaba como obsequios oro y plata cargados en venado. Sus abuelos también le contaron que dentro del Apu hay oro y un manantial y que se puede escuchar el ruido del agua que fluye" (Pastora de Huancabamba 2013)

La familia Huamani Condori ${ }^{20}$ (Huancabamba):

"Dicen que a Mama Simona la conocían antiguamente por Quimón. Cuando se hace pago con fe se tendrá éxito, pero los Apus te cumplen todo, pueden ser cosas buenas o malas.

Los cerros tenían hartas tarucas (venados) y los usaban como mulas de carga y Waynaccorccor, utilizaba a estos para regalarle al Apu Mama Simona oro y plata finalmente Waynaccorcor logro conquistar a Mamá Simona y se casaron."

Las denominaciones de Mama Simona: Cerrón Palomino, en relación con las cuestiones de filiación idiomática, sostiene que hay que tener en cuenta que aparte de la existencia de un trasfondo sustratístico de una o varias lenguas que precedieron al quechua, en la región del Cusco, los incas, no ya míticos sino históricos, hablaron primeramente el aimara y luego el quechua (Cerrón-Palomino 1998, 1999).

Esto significa que la nómina de las huacas, así como la de los topónimos y de muchas de las instituciones incaicas, bien podrían ser de filiación puquina, aimara, quechua o de naturaleza poliglósica, sin descartar la existencia de nombres que seguramente provienen de los antiguos idiomas de sustrato a los que desplazaron las lenguas mayores mencionadas.

Anterior a este nombre español Mama Simona, tuvo otros nombres como el de Apian (Polo de Ondegardo), Aspiran y Yauira (Sarmiento de Gamboa), Aspiran (Cristóbal de Molina el cusqueño), Apian (Bernabé Cobo) y Yauirac (Inédito de Cristóbal de Albornoz), luego en la extirpación de idolatrías se le denomina como Simón que se quechuiza a Quimon o Machuquimon, y que presenta dos versiones:

Simona era el nombre de una hacienda de esta jurisprudencia cuya dueña se llamaba así.

Simona era el nombre de una bruja malera que asentó sus reales en estas tierras.

En el caso de la región del Cusco, los dioses tutelares son Apus como el Salkantay y Auzangate, en el valle del Cusco los Apus son Pachatusan, Wanakawri, Senqa, Anawarque y Mama Simona; Casi todos los apus son masculinos, pero destaca uno de género femenino; en general son raros los Apus femeninos, en las cercanías del Cusco Mama Simona es quizás la única montaña femenina en esta región actualmente.

Avendaño, establece que al ser todos los Apus masculinos se genera en el imaginario colectivo la necesidad de tener un elemento complementario femenino para crear la vida, generándose una identidad.

18. Comunicación personal de Josefina Salón de 67años, natural de Ccorca, 2013

19. Pastora natural de Huancabamba, la escuche en una conversación informal, no quiso dar su nombre.

20. Comunicación personal de la familia Huamani Condori, de Huancabamba 


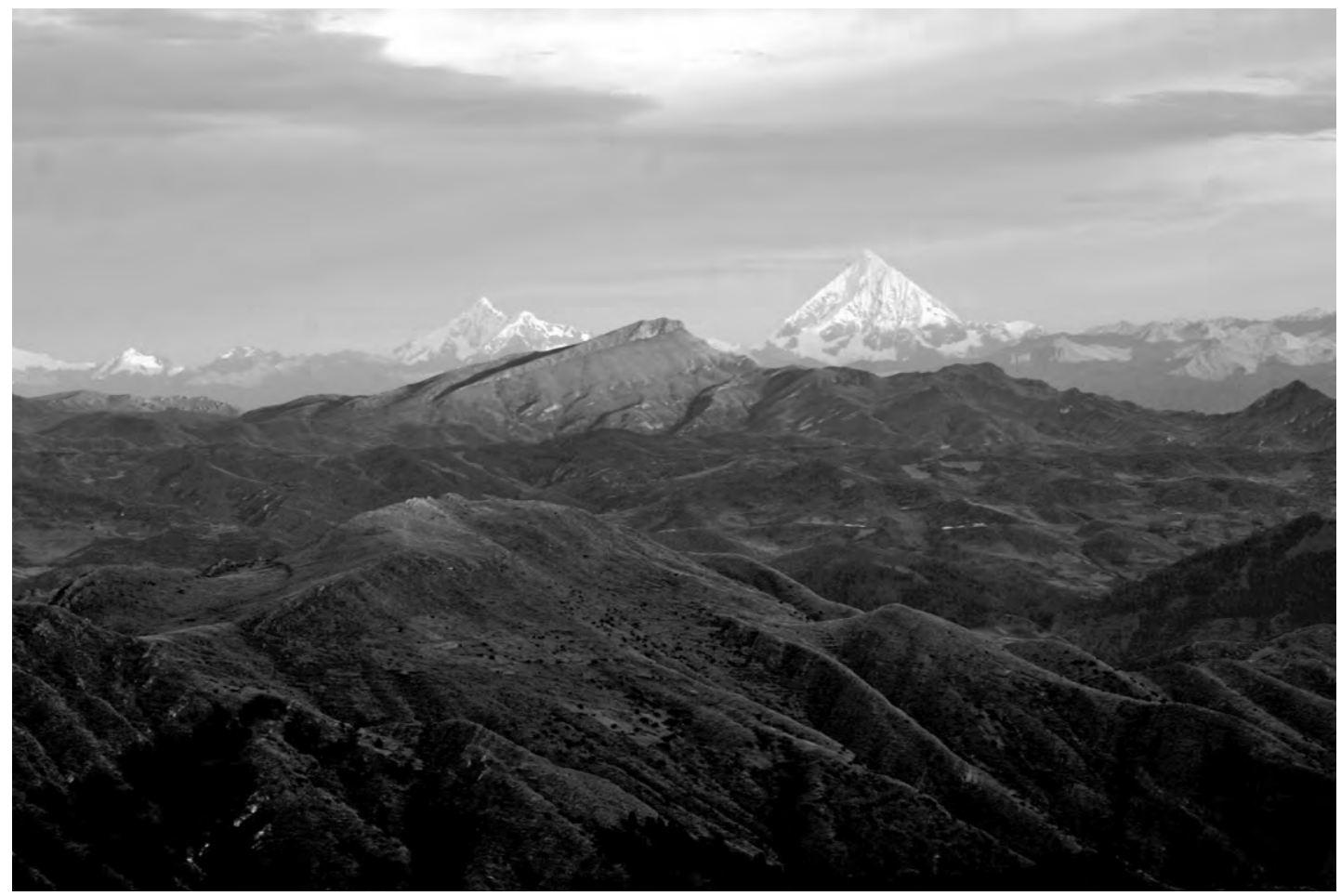

Figura 6: Al fondo en la derecha el macizo del Salkantay, al centro Mama Simona y más al fondo a la izquierda el Humantay (Foto cortesía Oscar Montufar)

El título de Mamacha alude fundamentalmente a vírgenes; en tiempos de la invasión española se produjo la extirpación de idolatrías; tal como lo mencionan muchos cronistas entre ellos el Obispo de la Peña Montenegro que considera que para destruir la idolatría y desarraigar supersticiones y hechicerías, derribaron los adoratorios, templos etc. y, reemplazar las apachetas con cruces (Valcarcel 1978). Luego asignarles nombres católicos ya sean masculinos o femeninos como es el caso de Mama Simona, el primer nombre católico fue el de Simón, que líneas abajo sustentaremos.

Frente a ello a Mama Simona, se le menciona que en el Corpus Christe, y porque en el pensamiento andino la virgen purificada tiene cierta advocación de identificación indígena con este Apu (la mujer es comparada con la tierra).

El Corpus Christi coincide con el It'u, fiesta más importante de carácter agrícola. Zuidema considera que el Apu Mama Simona pudo ser un lugar donde se realizaban ceremonias de culto y religión en torno a la agricultura, varios cronistas indican que en este apu se sacrificaban una llama al sol naciente y otro al sol poniente; estudios modernos realizados por Zuidema y otros, ubicaron una de las cuatro Saywas que rodean el cusco; era uno de los elementos confortantes del sistema de Ceques los cuales fueron utilizados con diversos fines como son de carácter agrario, calendárico, geográfico, político, etc.

Las Saywas se encontraban emplazadas en cuatro montañas las cuales fueron elementos referenciales a la salida y puestas del sol, elementos que funcionaban en relacion de los mal denominados intiwatanas y al usnu que se encontraba en la plaza central del Cusco determinando las variaciones de la posicion del sol y su desplazamiento (Medrano, Historia del Cusco I prehispanico). 
En el mundo andino solo hay Hanan Pacha y el Huju Pacha (arriba-adentro) y el Kay Pacha es el eje de estabilidad; el primer nivel sacerdotal está constituido por el "ayllu alto mesayoq". (Murillo s/f: 16). Por otro lado es el sacerdote que ha tenido una experiencia de visión e incorporación de poder de un "ayllu apu", espíritu de una montaña tutelar de una localidad por ejemplo el Apu Mama Simona o Alpera presidía la vida de los pobladores de Ccorca, de tal forma que también era una zona fronteriza dividiendo este mundo y el otro.

Cuando se extirpan las idolatrías y se impone la religión católica, apostólica y romana, el primer nombre asignado a este Apu, es el de Simón, el mismo que tuvo un propósito de hacer desaparecer su importancia como deidad prehispánica, que luego es variado o quechuizado como Quimón o Machuquimón, por los comuneros del área de influencia directa, de acuerdo a sus conveniencias o quizá como una respuesta a la imposición del nombre por parte de los españoles. Por lo que Simón lleva varios personajes del Nuevo Testamento, entre éstos figuran dos personajes evangélicos que invitaron a Jesús a compartir su comida.

Simón el fariseo recibe a Jesús a su mesa (Lc 7,40-43). Una pecadora, a la que se ha identificado en ocasiones de manera abusiva con María Magdalena entra en el comedor y vierte un pomo de perfume sobre los pies de Jesús. Simón el leproso, al que quizá pueda identificarse con el anterior, acoge también a Jesús a su mesa, la víspera de la Entrada en Jerusalén (Mt 6: Me 14.3). Durante esta comida Marta de Betanía, hermana de Lázaro derrama perfume sobre la cabeza de Jesús.

Otro personaje evangélico lleva este nombre: Simón de Cirene o Cireneo obligado a llevar la Cruz de Jesús en el camino del Calvario (Mt 32: Mc 15.21; Lc 23,26). El personaje principal de esta serie es, sin embargo Simón el apóstol, también denominado el cananeo.

Tradicionalmente en el Evangelio de Lucas y en los Hechos de los Apóstoles (Lc 6, 15; 1,13), Simón es denominado el «Zelotes». Este nombre, transcrito del go zelotes, es la traducción de la palabra aramea ganana: el apóstol miembro de una secta judía rigorista. También es llamado el cananeo, originario de Caná (Mt 10.4; Me 3. 18).

Como otros apóstoles, Simón desaparece después de Pentecostés. Tradiciones más o menos legendarias sitúan su actividad misionera en Egipto. Según una tradición apócrifa del siglo VI, predica posteriormente el Evangelio en Persia, con el apóstol Judas Tadeo, sufriendo ambos el martirio allí. Son degollados por haber derribado ídolos al concluir una discusión con sacerdotes paganos y magos.

Simón figura con Judas en numerosas representaciones (Luis Borras sá. Retablo de santa Clara, 1414, Museo de Vic). Las escenas generalmente representadas son las del martirio de los dos apóstoles y de la destrucción de los ídolos (de donde salen dos etíopes «negros y desnudos», según la Leyenda dorada de Santiago de la Vorágine). El apóstol está atado a una rueda, dos verdugos le cortan el pecho con una sierra de leñado (capitel, iglesia colegiata de Saint-Aubin en Guerande, siglo XII). En el siglo XVI Durero representa a Simón con una sierra en la mano (grabado de 1523).

Hasta el siglo XIII, el apóstol lleva en la mano un rótulo, después un libro. Posteriormente la sierra aparece como atributo específico; en el siglo XV, predomina definitivamente. En el siglo XVII Simón hojea a veces un libro. 


\section{Las Montañas como Objetos de Culto.}

Las etnias prehispánicas andinas en general, los Inkas en particular, parecen haber estado definidos en función del espacio habitado y la sacralización del paisaje (Niles 1992:347-357, Bauer 2000, Sanhueza 2004b). Una variedad de accidentes topográficos fueron transformados culturalmente en deidades o mitos que sirvieron para organizar los lugares cada vez más distantes y distintos del Cusco. Dentro de este esquema geográfico caracterizado por la variedad de formas y tamaños, donde todo lo natural parece haber sido objeto de culto, las montañas tuvieron un lugar de privilegio, especialmente si tenemos en cuenta la cantidad de energía invertida en los casi doscientos cerros de la cordillera donde se localizaron evidencias arqueológicas. En el Apu Mama Simona se tiene el Sector Estructuras, ubicada en la parte baja registrándose una serie de recintos irregulares y ovoides los cuales probablemente cumplieron la función de recintos, espacios de preparación espiritual, corrales, y otros, en la actualidad de todo este sector solo se llega a evidenciar algunas hileras de muro, los cuales tiene un ancho de 1.10 metros. Por el lado suroeste se tiene un corral la cual está adosado al afloramiento rocoso, el cual presenta 2 a 3 hileras de material lítico y su tipo de aparejo es de pirqado al seco.

La adoración a las montañas está lejos de ser un fenómeno particular en los Andes, por ejemplo, en el año 1519 Hernán Cortez, con el afán de impresionar a los aztecas ordenó a sus soldados que conquistaran la cima del volcán sagrado del imperio, el Popocatepetl de 5432 metros (Echevarría 1999).

En otros continentes también hay montañas sacralizadas, en Grecia los montes Olimpo, Licaón, Parnaso, Helicón, Citerón; en la India el Monte Mera; en Irán el Haraberezaiti; el Monte de los Países en Mesopotamia; en Turquía el Monte Nemrut, en Palestina el Monte Gerizín; en África el Kilimanjaro, el Mera y el Kenia; en el Tíbet el Monte Kailas y la mayoría de las montañas del Himalaya, y sabemos que los ejemplos continúan (Vitry 1997:16-23).

Las culturas americanas antes del apogeo de los inkas veían a las montañas como la materialización de sus deidades, por tal motivo y desde siempre le rindieron tributo, brindándoles ofrendas y plegarias. Cuando el estado Inka empezó a florecer y extender sus fronteras durante el siglo XV, hicieron propio este culto y construyeron en las elevadas cimas (huacas), pequeños edificios o recintos destinados a la religión y que hoy se los conoce bajo el nombre de "adoratorios de altura".

En estas construcciones los "sacerdotes" locales o provenientes del Cusco se encargaban de establecer el contacto con los apus o divinidades $\mathrm{y}$, de acuerdo a las circunstancias sociales, políticas o religiosas del estado realizaban sus ofrendas, en algunos casos humanos.

El volcán Misti (Perú) tuvo una erupción hacia 1440-1450 que produjo grandes daños a la Arequipa prehispánica, por tal motivo Inca Yupanqui realizó ofrendas para aplacar la ira del Apu (Chávez 2001:283-288). Excavaciones arqueológicas efectuadas en la cima del volcán dieron como resultado dos enterramientos, uno masculino y otro femenino, con tres cuerpos cada uno, los cuales fueron ofrendados al volcán (Beorchia Nigris 2001: 281-317)

Estos adoratorios poseían una existencia material y estaban relacionados con elementos concretos de la naturaleza como la fertilidad de los campos y fenómenos meteorológicos (Reinhard 1983: 27-62). Resulta interesante para el análisis antropológico este sincretismo entre el espacio geográfico, las geoformas. En la cordillera de los Andes se registraron a la fecha 199 montañas con restos arqueológicos, de las cuales el $96 \%$ se localizan al sur del Cusco, la desproporción se puede deber, entre otras explicaciones, a que históricamente las investigaciones se concentraron en el sector meridional, especialmente Argentina, Chile y Perú o bien, a que la adoración de las montañas y ofrenda de niños es mucho más antigua en esta región, tal como lo sugieren algunos autores (Gentile 1999). 
Uno de los rituales más importantes del calendario Inka fue la Capacocha o Capac Hucha que puede traducirse como "obligación real". De las cuatro direcciones del estado Inka algunos poblados enviaban uno o más niños al Cusco, para luego de las ceremonias allí oficiadas, regresar y ser ofrendados bajo la tierra. La ceremonia abarcaba montañas, islas y otros adoratorios o huacas que se localizaban en toda la extensión del Tawantinsuyu y servía para unir el espacio sagrado con el tiempo ancestral (McEwan y Van de Guchte 1992:369).

Se tiene conocimiento de 29 cuerpos localizados en diferentes latitudes, desde la Isla de la Plata en las costas ecuatorianas hasta el nevado El Plomo en Santiago de Chile, separados por una distancia de 3700 kilómetros. De quince montañas se extrajeron veintisiete cuerpos ofrendados en contextos de capacocha, la mayoría de éstas en alturas entre los 5000 y los 6700 metros, que es el margen de altura de las montañas sagradas del Salkantay (6271 msnm). Ausangate (6372) y probablemente Mama Simona (4450).

Las grandes distancias recorridas, las horas de trabajo invertidas en condiciones extremas propias de la alta montaña, las ofrendas humanas de niños y sus ajuares suntuosos, entre muchos otros elementos, dan cuenta de la necesidad de organizar el espacio a través de la significación religiosa, adaptando y construyendo nuevos paisajes acorde a la cosmovisión que se estaba imponiendo en nuevos territorios, esta construcción del paisaje está lejos de ser solo una cuestión conceptual, ya que se erigieron mojones, pilares, apachetas en el espacio inkanizado (Sanhueza 2004:481-492, Vitry 2002:177-191), además de caminos formalmente construidos hasta las altas cumbres (Astuhuamán 1999:127-147, Vitry 2005b).

Este espacio geográfico construido intencionalmente con determinadas significaciones, es un reflejo del poder del grupo étnico dominante que, como una de las tantas estrategias de dominación manipularon la narrativa del paisaje aprovechando el poder que tiene el espacio en la idiosincrasia andina y creando un espacio de poder en la montaña del Apu Mama Simona.

\section{El espacio con poder en los paisajes sagrados.}

Los Inkas, en un período breve de tiempo comprendido entre los siglos XV y principios del XVI, extendieron sus fronteras y dominio sociopolítico desde el Cusco a lo largo de la cordillera de los Andes, conformando uno de los estados más extensos y poblados de la América prehispánica. Este poder y el paisaje fueron sacralizados por miles de personas de diferentes grupos étnicos y lingüísticos que estuvieron bajo un estricto sistema de tributos y burocracia creado por los Inkas, que asumió necesariamente una dimensión espacial-territorial, plasmada en el paisaje y materializada en el espacio (Sánchez 1992), de manera tal que se puede percibir una utilización y manipulación de los elementos simbólicos preexistentes por parte del poder y a favor de una reestructuración social y espacial.

En este esquema de refuncionalización espacial, o en otro sentido, resignificación territorial, es una clara evidencia de que esta necesidad puede ser constatada en el proceso de colonización de un territorio, iniciada por la desestructuración espacial de una sociedad anterior y su reestructuración de acuerdo con el modelo social del colonizador o grupo dominante (Godelier 1978).

De esto se desprende que el espacio no es neutro, por el contrario, está plasmado de significaciones en tanto significantes espaciales, los que se refieren a la inscripción de la sociedad en el espacio, tomando elementos de la naturaleza o a las intervenciones artificiales; como significados culturales que es la lectura que la sociedad hace del espacio. Ambos tipos de significaciones generan puntos de referencia específicos, hitos marcados o significados en el terreno, que tienen la finalidad de organizar y ordenar el espacio. (Greimas 1980). Se puede decir que la cultura está conformada por términos 
y conceptos, que se encargan de decodificar lo real para recortarlo, estructurarlo y organizarlo. Estos signos poseen un valor descriptivo, pues nombran los lugares, la vida, la técnica, los seres, los fenómenos naturales, adquiriendo con el tiempo un contenido de carácter emotivo (Duncan 1990).

Esta creación social del espacio es una constante en las diferentes culturas, quienes crean y recrean el "Centro del Mundo", traspolando y reproduciendo este modelo o imagen de mundo ideal en diferentes escalas y lugares (Elíade 1994).

En este sentido y quizás con el objeto de legitimar la conquista, los inkas sacralizaron los espacios, creando un orden simbólico en el paisaje, otorgando a los elementos de la naturaleza una relevancia social diferenciada, a través de la demarcación de puntos fijos como las montañas y con diferente grado de significación.

Cuando los inkas ocuparon el espacio sagrado de los kollas adoptaron su historia como propia y las modificaciones del espacio expresaron las concepciones de ambos (Niles, 1992:347-357). Asimismo hicieron del Cusco algo más que una ciudad central por ser la capital o sede del poder político, fue el centro del cosmos inkaico, la zona sagrada por excelencia, la residencia de las huacas de todo el Tawantinsuyu, por ello, se preocuparon por reproducir en el vasto territorio y a menor escala "nuevos Cuscos" (Farrington 1998:53-59) o centros administrativos y religiosos de variado porte, repitiendo en ellos los elementos básicos de la arquitectura y la disposición espacial.

Gran cantidad de signos, iconos, símbolos fueron plasmados en el paisaje con la finalidad de transmitir un mensaje, conformando una unidad geopolítica del poder, plasmada en una serie de formas de ocupación del espacio, diseños arquitectónicos (kallancas, hornacinas, adoratorios de altura, etc.), morfología estandarizadas de vasijas, textiles, ofrendas, ceremonias y caminos, entre otros elementos que trascienden al lenguaje escrito y se vinculan con la oralidad, generando puntos de referencia específicos, hitos construidos o significados en el terreno y en el cuerpo social, que introdujeron un orden y facilitaron la comunicación entre los hombres y el mundo sobrenatural (Bauer 2000).

Esta construcción social del espacio o "lugar antropológico" está referida a “...lugares cuyo análisis tiene sentido porque fueron cargados de sentido, y cada nuevo recorrido, cada reiteración ritual refuerza y confirma su necesidad. Estos lugares tienen por lo menos tres rasgos comunes. Se consideran identificatorios, relacionales e históricos" (Auge 1995:58). Esta organización o construcción del espacio representa una de las prácticas colectivas e individuales que se manifiestan en el interior de un grupo social, generada por los hombres y entendida como estructuras de significación socialmente establecidas (Geertz 1992:20). Un sistema donde los signos interpretables o símbolos, interactúan, son aprehendidos y transmitidos por las culturas que los generaron, utilizando un espacio relativamente acotado en un tiempo determinado.

Pero espacio y tiempo son elementos dinámicos, de allí que las acciones sociales de cada tiempo se acumulan en el espacio y a través de la perspectiva histórica las sociedades recrean y legitiman la narrativa del paisaje.

Los sentidos informan que la montaña en su materialidad no se modificó, nada aparentemente la distingue de la anterior o las demás. Pero, para quienes la sacralizaron, su realidad de montaña se transforma en realidad sobrenatural, dejando de ser lo que era y cobrando connotaciones particulares. Ya no está en el caos del universo, está marcando un punto fijo, un lugar en el espacio. Esta construcción social del espacio es una constante en las diferentes culturas del mundo, quienes crean y recrean el "Centro del Mundo", transpolando y reproduciendo este modelo o imagen de mundo ideal de sí mismo en diferentes escalas y paisajes (Elíade 1994:38). 


\section{CAminos hacia los adoratorios DE ALTURA}

Según Vitry, los adoratorios de altura se investigan hace un poco más de medio siglo y el sistema vial Inka desde antes, sin embargo, los caminos ceremoniales que ascienden a las montañas con sitios arqueológicos poseen escasos antecedentes, como es el caso de Mama Simona.

$\mathrm{Su}$ presencia fue mencionada en algunas publicaciones (Rebitsch 1966:51-80, Niemeyer y Rivera 1983:91-193, Núñez 1981:49-57, Reinhard 1983.27-62 y 1997:105-129, Schobinger, 1986:297-317, Beorchia 1987, Hyslop 1992, Lynch 1996:187-203, Ceruti, 2003, Castro et al. 2004:439-451, entre otros), sin embargo, no fueron objeto de estudios sistemáticos hasta hace relativamente poco tiempo cuando las investigaciones de los adoratorios de altura se empezaron a integrar al sistema vial Inka de una manera más detallada y contextual, abordando el estudio de los caminos ceremoniales de las altas montañas como elementos de importancia para la comprensión de la geografía sagrada y el paisaje cultural andino (Astuhuamán 1999, Vitry 2000b, 2005b y 2006). En base a la información publicada y complementada con nuestras investigaciones de campo, tenemos que sobre un total de 199 montañas con evidencias arqueológicas en la cordillera de los Andes, en 32 de ellas (16\%) se registraron hasta el momento la presencia de caminos en sus laderas y/o cerca de las cumbres y en la base o proximidades de 45 montañas $(22,6 \%)$ pasa el Qhapaq Ñan o camino troncal.

Los caminos que ascienden por las escarpadas laderas hasta las cimas de las montañas sagradas de los tiempos prehispánicos, no fueron solo vías que conducían a esos lugares donde se celebraban los ritos propiciatorios, se trata de caminos ceremoniales o caminos sagrados (Castro et al. 2004:439-451,Vitry 2005), connotados de un simbolismo religioso especial y utilizados por una elite en circunstancias que el estado consideraba especiales. En nuestro caso el camino que sale desde la comunidad de Quiswarcancha hasta la cima de Mama Simona cumplía estos requisitos.

Fueron los canales de comunicación y acercamiento con los Apus, a quienes se les propiciaban valiosas ofrendas con fines tanto religiosos como políticos.

\section{APRoXimaciones FinALES}

Mama Simona es parte de los Apus tutelares que componen la geografía sagrada del valle del Cusco, con un escenario tangible desde donde se pueden apreciar Apus con una jerarquía de primer orden como el Salkantay y Ausangate, con un espacio sagrado donde se realizaron importantes acontecimientos mágico religiosos en épocas prehispánica y contemporánea, ubicado en la línea de frontera o división de dos suyos el de Contisuyo (Ccorqa) y Chinchaysuyo (Poroy) cuyas primeras denominaciones correspondieron a Upuyauira y Apian, como Apu es parte conformante del sistema de Ceques, fuente de vida que induce la reproducción, es protectora y sanadora que a su vez distribuye el agua sigue siendo reconocida con bajo perfil en nuestros tiempos, tiene una parentela sagrada a pesar de las denominaciones que recibió y anotadas por los cronistas como Apian (Polo de Ondegardo; 1571), Aspiran y Yauira (Sarmiento de Gamboa; 1572), Aspiran (Cristóbal de Molina el cusqueño), Apian (Bernabé Cobo; 1573), y Yauirac (Inédito de Cristóbal de Albornoz; 1653), luego en la extirpación de idolatrías se le denomina como Simón que se quechuiza a Quimon o Machuquimon, fue considerado como un espacio sagrado para la realización del culto a través de ceremonias como el Qhapaq Qocha, y el Haywarikuy, realizados solo en lugares que tenían una debida importancia, es también un espacio con poder con caminos especiales orientados hacia los adoratorios de media altura. Finalmente se la denomina como Mama Simona, cumpliendo labores de oráculo e influyendo en los pronósticos sobre el clima en el valle del Cusco. 


\section{Agradecimientos.}

A las personas que de una u otra forma contribuyeron en la realización de este trabajo, en especial al antropólogo Luis Negrón Alonso, por haberme permitido el uso de su documento inédito Qusqupa Seq'enkuna, Wakankuna (Los Seques y Wak'as del Cusco, a Gilberto Tarco, por la actualización del catastro arqueológico de Mama Simona y a mis alumnos Zoilo Arqque, Kely Bellota. y Karen Carrasco, por ser parte del equipo de campo.

\section{BibLIOGRAFÍA}

\section{ACADEMIA MAYOR DE LA LENGUA QUECHUA}

2005 Diccionario Quechua Español. 2º Edición. Cusco.

\section{ASTUHUAMAN GONZALES, Cesar}

1999 El Santuario de Pariacaca. Alma Mater No 17 ( $\mathrm{p}$ 127-147) Lima. Universidad Nacional Mayor de San Marcos.

AUGE, M.

1995 Los no lugares. Espacios del anonimato. Barcelona. España. Segunda edición. Gedisa.

AVENDAÑO FARFÁN, Ángel.

1995 Diccionario Enciclopédico del Qosqo. Municipalidad del Qosqo.

BAUER, S. Brian

2000 El espacio sagrado de los inkas. El sistema de Ceques del Cuzco. Perú. Editorial den Centro Bartolomé de Las Casas-Cusco.

BEORCHIA NIGRIS, A.

1987 El Enigma de los Santuarios Indigenas de Alta Montaña San Juan, Argentina. Revista del Centro de Investigaciones Arqueológicas de Alta Montaña (CIADAM). Tomo 5 U.N.S.J.

BOLIVVAR YAPURA, Wilber

2015 Cambio en el Paisaje Cultural de la Montaña del Salkantay y su impacto en las ideologías locales. El caso de Soraypampa (prov. de Anta, región del Cusco). Tesis para optar el grado académico de Magister en Gestión del Patrimonio Cultural, en la Universidad Nacional Mayor de San Marcos. Facultad de Ciencias Sociales. Unidad de Post Grado.

BOLÍVAR YAPURA, Wilber y DUEÑAS, Yony

2013 La Montaña Sagrada del Salkantay. Su Paisaje, Poder y Ancestros. Arqueología y Sociedad № 26. Universidad Nacional Mayor de San Marcos, Centro Cultural de San Marcos, Museo de Arqueología y Antropología. Pág. 229-248.

CASTRO, V.; VARELA, V.; ALDUNATE, C. y E. ARANEDA.

2004 Principios orientadores y metodología para el estudio del Qapaq Ñan en Atacama: desde el portezuelo del Inka hasta Rio Grande. Chile. Chungara, Revista de Antropologia Chilena, volumen $36, \mathrm{~N}^{\circ} 2$, pp. 439-431.

CERRÓN PALOMINO, Rodolfo.

1998 El cantar de Tupac Inca Yupanqui y la lengua secreta de los incas. Revista Andina, 32, pp. 417-452. 1 
1999 Tras las huellas del aimara cuzqueño. Revista Andina, 33, pp. 137158.

CERUTI, M.C.

2003 Llullaillacu. Sacrificios y ofrendas en un Santuario Inca de Alta Montaña. Argentina EUCASA. Universidad Católica de Salta.

1999 Cumbres Sagradas del Noroeste Argentino. Avances en Arqueología de Alta Montaña y Etnoarqueología de Santuarios Andinos. EUDEBA, Buenos Aires.

COBO, Bernabé.

1653/1964 Historia del Nuevo Mundo. Biblioteca de Autores Españoles, tomos 91 y 92. Madrid: Ediciones Atlas.

CORI DEL M., Roxana y Baca V., José L.

2004 Interpretación. Pachatusan-Prospección Arqueológica. Tesis para optar al Título Profesional en Arqueología, presentado a la UNSAAC Facultad de Ciencias Sociales Departamento Académico de Antropología, Pág. 183

CORNEJO, Miguel

1995 Arqueología de Santuarios Incas en la Guaranga de Sisicaya, Valle de Lurín. Tawantinsuyu, Canberra,

CHÁVEZ CHÁVEZ, J.A.

2001 Investigaciones arqueológicas de alta montaña en el sur del Perú. Chile. Chungara, vol. 33, $\mathrm{N}^{\circ} 2$ : 283-288.

DUCHET-SUCHAUX Y PASTOUREAU

1996 Santos de la Iglesia del Oriente. Guía Iconográfica de la Biblia y los Santos, Versión española de Cesar Vidal, Alianza Editorial, impreso en España Pág. 353-356.

DUNCAN, J.S.

1990 The cityas Text: The Politics of Landscapes Interpretation in the Kandyan Kingdom. Cambridge University Press.

DUVIOLS, Pierre

1967 Un Inedit de Cristóbal de Albornoz: La Instrucción para descubrir todas la Guacas del Piru sus camayos y Haziendas. In Journal de la Societe des Americanistes. Tome 56 Nº 1, 1967 Pág. 7-39

ESCOBAR MEDRANO, J. E.

1998 Historia del cusco I prehispanico. Cusco perú.

ELIADE, Minceo

1994 Lo sagrado y lo profano. Colombia, 9na edición. Colección Labor 2 edición Labor.

FARRIGTON, Ian

1998 The concept of Cusco. Tahuantinsuyo. Camberra. (5): 53-59. Brolga Press Pty Ltd. Australia. Australian National University. 
GENTILE, M.

1999 Huacca Muchay-Religión indígena. Argentina, Instituto Nacional Superior del Profesorado de Folklore" Guevara Carazas.

GEERTZ, C.

1992 La interpretación de las Culturas. España quinta reimpresión, Ed. Gedisa.

GODELIER, Maurice

1978 The concept of social and economic formation: The Inca example. Perspectives in Marxist Anthropology. Cambridge University Press, 1974: 63-69.

GREIMAS, A.J.

1980 Semiótica y Ciencias Sociales. Fragua.

HYLOP, John

1992 Qhapaqñañ. El sistema vial incaico. Perú Instituto Andino de Estudios Arqueológicos.

INSOLL, Timothy

2008 Arqueología del culto y la Religión. Arqueología Conceptos Clave. Colin Renfrew y Paul Bahn (Eds) AKAL Universitaria, Serie Conceptos Clave 2006 (Pág.70)

MC EWAN, C. y M, VAN DE GUCHTE

1992 El tiempo ancestral y el espacio sagrado ritual estatal incaico. The Ancient Ameritas: Art from sacred lansdcapes, ed Richard Townsend, pp. 359-371. The Art. Institute of Chicago.

MOLINA, Cristóbal De. El Cuzqueño.

(1573/1947) Ritos Y Fabulas De Los Incas Cap. VI - Cultos, Sacrificios y Festividades. Colección Eurindia 14 Buenos Aires: Editorial Futuro

MURILLO, J. N.

s/f Mistica. El Antoniano, 16-17.

NEGRÓN ALONSO, Luis

2015) Qusqupa Seqénkuna, Wakankuna (los Seques y Wakas del Cusco). Inédito, Comunicación personal.

NILES, S.,

1992 La arquitectura incaica y el paisaje sagrado. The Ancient Ameritas: Art from sacred ladscapes. Ed. Richard .F Towsend, pag 347-357.

NIEMEYER, H. y M. RIVERA

1983 Un camino inca en el despoblado de Atacama. Boletín de Prehistoria de Chile, Santiago. 9: 91:193. Departamento de Ciencias Sociológicas y Antropológicas, Universidad de Chile.

NÚÑEZ HENRÍQUEZ, P.

1981 El camino del inca. Revista CRECES, Vol 2: 49-57. 
LÓPEZ PACHECO, Gorka y VILCHES PINARES, Magdalena C.

1997 Estudio Económico del Yacimiento Salino de Occopata. Tesis para optar el título de Ingeniero Geólogo (UNSSAC).

LYNCH, T.

1996 Inca roads in the Atacama: Effects of later use by mounted travellers: Chile. Dialogo Andino. 14/15, 1995-1996.pp. 187-203. Universidad de Tarapaca.

PEREZ BOCANEGRA, Juan

1631 Ritual, formulario e institución de curas, para administrar a los naturales de este Reyno. Lima: Jerónimo de Contreras, Convento de Santo Domingo

PIZARRO, Pedro

1978 Relación del descubrimiento y conquista de los reinos del Perú [1572]. Lima: PUCP.

POLO DE ONDEGARDO, Juan

1571/1917 Relación de los adoratorios de los indios en los cuatro caminos (zeques) que salían del Cuzco: pp. 3-43. (2a. parte) Colección de Libros y Documentos Referentes a la Historia del Perú, serie 1, tomo 4, pp. 3-204. Lima: Imprenta y Libreria Sanmarti y Ca.

REBITSCH, M.

1966 Santuarios en altas cumbres de la Puna de Atacama. Mendoza. Anales de Arqueología y Etnología 21: 51.80. Universidad Nacional de Cuyo.

REINHARD, Johan

1983 Las Montañas Sagradas: Un estudio etnoarqueológico de ruinas en las altas cumbres andinas Chile. Cuadernos de Historia. (3): 27-62. Universidad de Chile.

REINHARD, Johan

1997 Llullaillaco: Investigación del yacimiento arqueológico más alto del mundo. Mendoza, Argentina. Anales de Arqueología y Etnología. (49/49): 105-129, años 1993/1994. Universidad Nacional de Cuyo. // (2002). "Machupicchu. El centro sagrado". Instituto Machu Picchu. Cusco, Cimagraf .Pág. 21, 35.

SARMIENTO DE GAMBOA, Pedro

1572/1965 Historia de los Incas. Segunda parte de la Historia General Llamada Indica. Biblioteca de Autores Españoles, tomo 135, pp. 193-279. Madrid: Ediciones Atlas.

SÁNCHEZ GARRAFA, Rodolfo

2015 Apus o dioses de los cerros. Apus de los cuatro Suyos. Construcción del mundo en los ciclos mitológicos de las deidades montaña. Primera reimpresión febrero 2015. Instituto de Estudios Peruanos IEP y Centro de Estudios Regionales Andinos Bartolome de las Casas (CBC) Pag.269-281.

SÁNCHEZ, J.E.

1992 Geografía Política. España. Colección Espacios y Sociedades, Serie N²3. Síntesis. 
SANTA CRUZ PACHACUTI YAMQUI, Juan de

(1613/1993) Relación de antigüedades deste reino del piru. Biblioteca de Autores Españoles. (Crónicas Peruanas de Interés Indígena). Madrid: Ediciones Atlas. 1613/1993. pp. 279-319

SANHUEZA, $C$.

2004 Medir, amojonar, repartir: Territorialidades y practicas demarcatorias en el camino incaico de Atacama (II Región, Chile). Chungara 36 (2): 481-492.

SCHOBINGER, J.

1986 La red de Santuarios de Alta Montaña en el Cuntisuyo y el Collasuyu: Evolución general y Problemas interpretativos. Córdoba, Argentina. Comechingonja. (Número Especial): 297-317.

TARCO SÁNCHEZ, Gilberto

2014 Expediente Técnico de Delimitación Apu mama Simona

VALCARCEL, Luis. E.

1978 Historia del Perú antiguo. Lima-Perú: Juan Mejia Baca

VITRY, C.

1997 Arqueología de alta montaña. Argentina. Yachayruna. Revista de Divulgación Científica. Grupo de estudios de Ciencias Sociales. Facultad de Humanidades. UNAS. Año 1, № 1 pág. 16-23.

2002 Apachetas y mojones, marcadores espaciales del paisaje prehispánico. revista 1. Escuela de Historia. Año 1. Vol 1.pp 177-191.

2005 Contribución al estudio de caminos de sitios arqueológicos de altura. Volcan Llullaillaco (6,739). Salta-Argentina. XV Congreso Nacional de Arqueología Argentina. Rio Cuarto. Córdova.

2006 Arqueología del Nevado de Chañi. Nevado de Chañi. Gonzales, E. y C. Vitry. Ed. Artes Gráficas, Salta.

ZAPATA, Julinho.

1998 Los cerros sagrados: Panorama del periodo formativo en la cuenca del Vilcanota Cuzco. Boletín de Arqueología N² 2. Lima: PUCP Pág. 307

ZUIDEMA, Tom

1995 El sistema de ceques del Cusco. Lima-Perú: Pontificia Universidad Catolica del Perú.

ZECENARRO BENAVENTE, Germán

2003 Apus Tutelares y Asentamientos del Cusco Preinka. Boletín de Arqueología PUCP N 7. Identidad y Transformación en el Tawantinsuyu y en los Andes coloniales Perspectivas arqueológicas y etnohistóricas. Segunda Parte. Departamento de humanidades, Especialidad de Arqueología. Pontificia Universidad católica del Perú. 